Original Research

\title{
What Do Our Nurses Know about Managing Patient with Permanent Pacemakers?
}

\author{
Muhamad Al Muizz Ismail ${ }^{1}$, Nor Marini Ibrahim² ${ }^{2}$ and Muhammad Kamil Che Hasan ${ }^{3}$ \\ ${ }^{1}$ Coronary Care Unit, Hospital Universiti Sains Malaysia, Kelantan, Malaysia \\ 2 Open University Malaysia, Kelantan, Malaysia \\ ${ }^{3}$ Department of Medical-Surgical Nursing, Kulliyyah of Nursing, International Islamic University Malaysia, \\ Pahang, Malaysia
}

\begin{abstract}
Introduction: The number of patients with pacemaker implant is increasing in the health services sector in Malaysia, which requires nurses to have expertise in patient care with pacemaker implantation. Therefore, this study was conducted to analyse the level of knowledge among nurses regarding the management of patients with pacemaker implantation.
\end{abstract}

Methods: A cross-sectional study was conducted through purposive sampling among all nurses working at the critical care unit, intensive care unit, cardiac rehabilitation ward, investigation clinical laboratory, and non-invasive clinical laboratory in a public hospital in Kelantan. A questionnaire consisted of demographic data and nurses' knowledge was distributed. Data were analysed for descriptive analysis and using Pearson correlation test.

Results: Results from all respondents ( $n=70)$, show $48.6 \%$ of the respondents had moderate knowledge about patient management with pacemaker implantation, $32.9 \%$ had a low level of knowledge and only 13.6\% had high knowledge regarding management of patient with pacemaker implantation. There is a significant difference between the level of knowledge and demographic data, that is between the level of education $(p=0.027)$, age $(p=0.011)$ and length of service $(p=0.015)$. There is no significant relationship between knowledge and demographic data, such as gender $(\mathrm{p}=0.481)$, marital status $(\mathrm{p}=0.315)$, and post-basic $(\mathrm{p}=0.067)$.

Conclusion: Level of knowledge among nurses about the management of patient with pacemaker implantation is low to moderate. Additional education and exposure among nurses are needed to enhance the knowledge of nurses and improve the quality of care among patients with pacemaker implant.

\section{ARTICLE HISTORY}

Received: May 02, 2020

Accepted: August 08, 2020

\section{KEYWORDS}

knowledge; management; nurses; pacemaker

\section{CONTACT}

Muhammad Kamil Che Hasan $\triangle$ mkamil@iium.edu.my

Department of MedicalSurgical Nursing, Kulliyyah of Nursing, International Islamic University Malaysia, Pahang, Malaysia

Cite this as: Ismail, M. A. M., Ibrahim, N. M., \& Hasan, M. K. C. (2020). What Do Our Nurses Know about Managing Patient with Permanent Pacemakers?. Jurnal Ners, 15(2), 157-161. Doi:http://dx.doi.org/10.20473/in.v15i2.18925

\section{INTRODUCTION}

According to the World Health Organization (WHO), in 2016, an estimated 17.9 million deaths worldwide are caused by cardiovascular disease (WHO, 2020). In Malaysia, in 2012, statistical data showed that $295.8 \%$ of deaths per 100,000 population in Malaysia were due to cardiovascular disease (WHO | Global Health Observatory (GHO) data, 2019). It is also estimated that around 450,000 deaths worldwide are caused by sudden cardiac death (Stecker et al., 2014). A poor electrical conduction system of the heart is seen as a critical issue and can result in death or cause complications such as congestive heart failure (Burri
\& Varma, 2013). Currently, the problem of heart rhythm can be treated with the use of a permanent pacemaker (PPM) which helps the heart when the rate of heart rhythm drops below 60 per minute. It acts as an artificial sino-atrial node and helps drain the heart's electrical system to raise the heart rate to 60 beats per minute (Boink, Christoffels, Robinson, \& Tan, 2015). Nurses should play a role in caring for patients with PPM, through updating knowledge of pacemaker by attending continuous training and education to ensure comprehensive care (Humphreys, 2013). The knowledge of pacemaker management is very crucial, and a key factor to 
ensure that the patients are fully informed and understand about the pacemaker. Nurses are reported to have a key role to liaise with the multidisciplinary team in providing information to patients and family members before surgery (Riley, 2015).

The pacemaker will be part of the patient's life expectancy and, therefore, the assessment of patient and caregiver knowledge is important to prevent early complications and dysfunction and that immediate treatment can be provided (Hatchett \& Thompson, 2002). The pacemaker is also reported to induce musculoskeletal attention of the diaphragm, the pectoral or the intercostal muscles due to normal extracardiac stimulation (Rasmussen \& Pareek, 2014). The implantation of pacemaker is also reported in reducing the incidence of falls, fall-related fractures and fall-related injuries among patients with sinus node dysfunction (Brenner et al., 2017). These ongoing updates and challenges among patients with pacemaker indicate the need for nurses to update their knowledge. Currently, there is no research on nurses' knowledge of pacemaker management in the local context. It is very crucial to identify the basic information related to the knowledge of nurses to provide ongoing awareness of the updated information of pacemaker. Therefore, this study was conducted to measure the level of knowledge among nurses regarding the management of patients with pacemaker implantation.

\section{MATERIALS AND METHODS}

A descriptive cross-sectional study was conducted. All nurses at cardiology related clinical area (coronary care, intensive care, cardiac rehab ward, invasive cardiac catheterization lab, and non-invasive cardiac lab) were purposively sampled to determine their levels of knowledge concerning pacemaker in one of the hospitals in Kelantan.

The questionnaires used in this study were adapted from HadiAtiyah ( 2016) through back and forward translation process by a group of three content experts to ensure the reliability and validity of the questionnaire. The questionnaire contained two parts: Part A, Sociodemographic Data; Part B, Knowledge. For demographic data, gender, age, marital status, education level, job placement, level of qualification and length of service in years were asked. The Part B questions (10 items) were related to nurses' knowledge, including the basic concepts of pacemaker, information on pacemaker and temporary pacemaker (TPM) as well as basic nursing knowledge. Responses to the statements were measured using a 5-point Likert scale: "strongly agree," "agree," "not sure," "disagree," and "strongly disagree." A pilot study was conducted to determine whether the instrument used in the measurement has high reliability and validity. The pilot study was conducted using 10 nurses and revealed a Cronbach's alpha value of 0.7 . If the Cronbach's alpha value reaches 0.5 and above, it shows that the research questions are appropriate and applicable (Bowling, 2002). The higher the value of the reliability of a measuring item, the better the outcome is.

Data collection procedure: After obtaining ethical approval [OUM/5.7/2.1.1/469.3/303-17(006)], we executed the study for six months beginning February 2017. All nurses aged 20 years and above with a minimum of six months of clinical experience were purposively selected in the respective area and approached to participate in this study. We used Krejcie and Morgan sample size scheduling as a means of calculating sample size for this study (Krejcie \& Morgan, 1970). According to the table, the sample size is based on the study population (70 nurses) and the sample size required is 59 people. The researcher distributed the questionnaire to 70 respondents and all respondents returned the completed questionnaire in response. Before the data collection, written consent was obtained from respondents. The respondents answered the questionnaire themselves, which took about seven to ten minutes. The respondents returned the completed questionnaires to the researcher, who checked them.

All data collected were kept confidential. The data were analysed using SPSS version 24, and the descriptive analysis results were presented in tables as frequency and percentage for the distribution of the data. Pearson's correlation coefficient was used to measure the relationship between knowledge and demographic characteristics. The results for associations between variables are also presented in tables, interpreted based on the significant $\mathrm{p}$-value of $\alpha=0.05$.

\section{RESULTS}

Table 1. Sociodemographic Data of Respondents $(n=$ 70)

\begin{tabular}{lcc}
\hline \multicolumn{1}{c}{ Variable } & $(\boldsymbol{n})$ & $\mathbf{( \% )}$ \\
\hline Gender & & \\
$\quad$ Male & 28 & 40.0 \\
Female & 42 & 60.0 \\
Age & & \\
$\quad 20-34$ & 38 & 54.3 \\
35-54 & 32 & 45.7 \\
Marital status & & \\
Single & 45 & 64.3 \\
$\quad$ Married & 25 & 35.7 \\
Level of education & & \\
$\quad$ Diploma & 48 & 68.6 \\
Bachelor's degree & 17 & 24.3 \\
$\quad$ Master's degree & 5 & 7.1 \\
Specialisation course & & \\
With post-basic & 32 & 45.7 \\
$\quad$ Without post-basic & 38 & 54.3 \\
Length of service & & \\
$\quad$ 5 years & 4 & 5.7 \\
5-10 years & 29 & 41.4 \\
11-20 years & 27 & 36.6 \\
$>$ 21 years & 10 & 14.3 \\
\hline
\end{tabular}


Table 2. Level of Knowledge Regarding Pacemaker ( $\mathrm{n}=70)$

\begin{tabular}{lccc}
\hline & Level & Frequency $(\boldsymbol{f})$ & Percentage (\%) \\
\hline High & 13 & 18.6 \\
Moderate & 34 & 48.6 \\
Low & 23 & 32.9 \\
\hline
\end{tabular}

Table 3. Correlation between Knowledge Score and Sociodemographic Data

Knowledge score

\begin{tabular}{|c|c|c|c|c|}
\hline & Coefficient, $r$ & P-value & Mean & Standard deviation (SD) \\
\hline Gender & -0.86 & 0.481 & 1.60 & 0.49 \\
\hline Age & $0.301^{*}$ & 0.011 & 2.45 & 0.5 \\
\hline Marital status & -0.122 & 0.315 & 1.36 & 0.48 \\
\hline Level of education & $0.265^{*}$ & 0.027 & 1.38 & 0.62 \\
\hline Specialisation course & -0.220 & 0.067 & 1.54 & 0.50 \\
\hline Length of service & $0.289^{*}$ & 0.015 & 2.61 & 0.80 \\
\hline
\end{tabular}

*. Correlation is significant at the 0.05 level (2-tailed).

Table 1 presents the detailed distribution of sociodemographic data among the respondents. This study included a total of 70 respondents, more than the required by the estimated minimum sample size of 59 . There were 42 female respondents (60\%), age range from 20-34 years was 38 (54.3\%). For the level of education, 48 respondents obtained diploma (68.6\%) while 32 (45.7\%) respondents have specialisation certificate in cardiac nursing. For distribution of service, this was less than five years $(n=4,5.7 \%)$, five to ten years $(n=29,41.4 \%), 11-20$ years $(n=27,36.6 \%)$ and more than 21 years $(n=10$, $14.3 \%)$.

Meanwhile, regarding knowledge of pacemaker, a questionnaire with a total of ten questions measured the level of knowledge on pacemaker. As presented in Table 2, almost half of the respondents have a moderate score $(n=13,48.6 \%)$, while a total of 13 respondents achieved a high score (18.6), and 23 respondents (32.9\%) has a low score, particularly in information on the device.

Table 3 shows the results of sociodemographic data and level of knowledge in detail. Based on the data analysis using a Pearson correlation test, there was a significant association between age and knowledge: $r=0.301, p=0.011$; level of education and knowledge: $r=0.265, p=0.027$; and length of service: $r=0.289, p=0.015$, while gender, marital status and specialisation course have no association with the level of knowledge regarding pacemaker among nurses.

\section{DISCUSSION}

This study indicated that the level of knowledge among nurses about the management of pacemaker is low to moderate. Most nurses in this study generally need to increase their knowledge about patient management with pacemakers, particularly information about the device, as compared to another study in Iraq (HadiAtiyah, 2016). Nurses need to educate the management of a patient with a cardiac problem, including a pacemaker. The development of professionalism is an activity that enhances the level of competence in terms of knowledge, skills and attitudes and the effectiveness of an individual's role in performing any given any task (Mohd Yusoff, Firdaus, Jamaludin, \& Che Hasan, 2019).

Continuous education is needed to enhance the level of knowledge, skills and competencies in the treatment of patients. Similar to a study in Egypt, nurses' knowledge and practices related to patient management and cardiac implantation devices are still unsatisfactory, while nurses' knowledge levels are low (Ali, Youssef, Mohamed, \& Hussein, 2014). The study has concluded that the source of knowledge of nurses regarding cardiac implantation device in relation to the topic is inconsistent with the nursing curriculum and has a profound impact on nurses' knowledge of cardiac implantation. Meanwhile, the lack of exposure and co-operation between each of the team disciplines led to the failure of nurses to have extensive knowledge of management of a patient with cardiac implantation devices. In addition, most nurses had low knowledge prior to the tests and satisfactory results after the tests on nurses as reported (Mahramus et al., 2013).

Moreover, it is important for nurses to have the knowledge and skills of cardiac implantation and specific care for patients with cardiac implantation (Ali et al., 2014). This finding is supported by Faisal in which he also recognised that nurses' knowledge and skills play a key role in providing counselling and care to patients requiring cardiac implantation so as to enable nurses to meet the complex needs (Ameen, 2017). Therefore, the need for nurses to receive ongoing training and education is very crucial.

Through bivariate analysis, this study also revealed that age and length of service play a significant role in influencing nurses' knowledge for the management of patients with pacemaker. Most nurses are from the age group of 20-34 years and have less work experience. This is supported by another study where, through their research on the practice and perception of delirium in intensive care units in Egypt, studies show 75\% of respondents are within the range of this study (Ali Elfeky \& Shoeib Ali, 2013).

From the findings, we recommended some strategies to improve nurses' knowledge of management of patients with pacemaker. Firstly, 
continuous nursing education regarding pacemaker among nurses with the collaboration of cardiologists to help further understandings of the nature of pacemaker and its relatedness. This could promote the development of a positive patient safety culture among healthcare professionals (Nurumal, Sabran, Hamid, \& Hasan, 2020). Researchers involved in the study also should consider cultural context as, in Malaysia, many issues involving cultural surroundings were reported (Aris, Sulaiman, \& Che Hasan, 2019; Mohd Sharif, Che Hasan, Che Jamaludin, \& Zul Hasymi Firdaus, 2018). Secondly, interprofessional learning activities could also be done to engage with the understanding of the management of pacemaker in the different fields, namely cardiovascular technologist, pharmacy, nutrition and therapist. Such instances could lead the nurses to understand and be able to adjust the mode of pacemaker and the process of checking the specific pacemaker function, maintenance and follow-up of pacemakers and routine checks for patients. Thirdly, regular assessment for nurses regarding the care of patients with cardiovascular problems, particularly pacemaker, in all cardiology-related units. It could lead to provide good practice of working, improve skills, and update the knowledge from time to time. Limitation of this study could be the small number of sample size and focusing only on one hospital.

\section{CONCLUSION}

As a conclusion, the level of knowledge among nurses regarding pacemaker is moderate which requires a numbers of actions to increase the level. Level of education and length of service indicated the need for continuous education to promote understanding of the management of patients with pacemaker in general and provide full support to patients in need. Further bigger scale research in different settings also is suggested to generalise the findings.

\section{REFERENCES}

Ali Elfeky, H., \& Shoeib Ali, F. (2013). Nurses' Practices and Perception of Delirium in the Intensive Care Units of a Selected University Hospitals in Egypt. Journal of Education and Practice, 4(19), 61-70. Retrieved from www.iiste.org

Ali, N. S., Youssef, W., Mohamed, A., \& Hussein, A. (2014). Nurses' knowledge and practice regarding implantable cardiac devices in Egypt. British Journal of Cardiac Nursing, 10(1), 551-557. https://doi.org/10.12968/bjca.2015.10.1.34

Ameen, F. (2017). Knowledge of Cardiology Nurses, Regarding Care of Patients with Permanent Pacemakers and Implantable Cardioverter Defibrillators in Karachi Pakistan. Prehospital and Disaster Medicine, 32(1), S148-S149. https://doi.org/10.1017/s1049023x17004095

Aris, A., Sulaiman, S., \& Che Hasan, M. K. (2019). The influence of music therapy on mental well-being among postoperative patients of total knee arthroplasty (TKA). Enfermeria Clinica, 29(2), 16-
23. https://doi.org/10.1016/j.enfcli.2019.04.004

Boink, G. J. J., Christoffels, V. M., Robinson, R. B., \& Tan, H. L. (2015). The past, present, and future of pacemaker therapies. Trends in Cardiovascular Medicine, 25(8), 661-673. https://doi.org/10.1016/j.tcm.2015.02.005

Bowling, A. (2002). Research methods in health: investigating health and health services. Open University Press.

Brenner, R., Ammann, P., Yoon, S.-I., Christen, S., Hellermann, J., Girod, G., ... Kühne, M. (2017). Reduction of falls and fractures after permanent pacemaker implantation in elderly patients with sinus node dysfunction. Europace: European Pacing, Arrhythmias, and Cardiac Electrophysiology: Journal of the Working Groups on Cardiac Pacing, Arrhythmias, and Cardiac Cellular Electrophysiology of the European Society of Cardiology, 19(7), 1220-1226. https://doi.org/10.1093/europace/euw156

Burri, H., \& Varma, N. (2013). Remote device management in patients with cardiac complaints. Cardiac Electrophysiology Clinics, 5(3), 337-347. https://doi.org/10.1016/j.ccep.2013.05.005

HadiAtiyah, H. M. D. H. (2016). Nurses, Knowledge Concerning an Implantation Pacemaker For Adult Patients with Cardiac Rhythm Disorder at AlNassirrhyia Heart Center.

Hatchett, R. P., \& Thompson, D. R. (2002). Cardiac nursing : a comprehensive guide.

Humphreys, M. (2013). Nursing the Cardiac Patient. Blackwell. https://doi.org/10.1002/9781118785331

Krejcie, R. V., \& Morgan, D. W. (1970). Determining Sample Size for Research Activities. Educational and Psychological Measurement, 30(3), 607-610.

Mahramus, T. L., Penoyer, D. A., Sole, M. Lou, Wilson, D., Chamberlain, L., \& Warrington, W. (2013). Clinical nurse specialist assessment of nurses' knowledge of heart failure. Clinical Nurse Specialist, 27(4),198-204. https://doi.org/10.1097/NUR.0b013e31829557 35

Mohd Sharif, N. A., Che Hasan, M. K., Che Jamaludin, F. I., \& Zul Hasymi Firdaus, M. K. (2018). The need for first aid education for adolescents. Enfermería Clínica, 28(Supplement 1), 13-18. https://doi.org/10.1016/S1130-8621(18)300287

Mohd Yusoff, N. S., Firdaus, M. K. Z. H., Jamaludin, F. I. C., \& Che Hasan, M. K. (2019). The need for educating healthcare professionals regarding good musculoskeletal health practice. Enfermería Clínica, 29(2),579-584. https://doi.org/10.1016/j.enfcli.2019.04.089

Nurumal, M. S., Sabran, N. M., Hamid, S. H. A., \& Hasan, M. K. C. (2020). Nurses' Awareness on Patient Safety Culture in A Newly Established University Hospital. Jurnal Keperawatan Indonesia, 23(2). https://doi.org/10.7454/jki.v0i0.1088

Rasmussen, I. K. B., \& Pareek, M. (2014). A video demonstration of pacemaker-induced pectoral 
muscle stimulation. BMJ Case Reports. https://doi.org/10.1136/bcr-2013-200697

Riley, J. (2015). The Key Roles For The Nurse In Acute Heart Failure Management. Cardiac Failure Review, 1(2), 123-127. https://doi.org/10.15420/cfr.2015.1.2.123

Stecker, E. C., Reinier, K., Marijon, E., Narayanan, K., Teodorescu, C., Uy-Evanado, A., ... Chugh, S. S. (2014). Public health burden of sudden cardiac death in the United States. Circulation: Arrhythmia and Electrophysiology, 7(2), 212-2 https://doi.org/10.1161/CIRCEP.113.001034 WHO. (2020). Cardiovascular diseases (CVDs). Retrieved from World Health Organisation website: https://www.who.int/news-room/factsheets/detail/cardiovascular-diseases-(cvds)

WHO | Global Health Observatory (GHO) data. (2019). WHO. 